\title{
Pulmonary function and exercise capacity after lung resection
}

\author{
C.T. Bolliger, P. Jordan, M. Solèr, P. Stulz, M. Tamm, Ch. Wyser, M. Gonon, A.P. Perruchoud
}

Pulmonary function and exercise capacity after lung resection. C.T. Bolliger, P. Jordan, M. Solèr, P. Stulz, M. Tamm, Ch. Wyser, M. Gonon, A.P. Perruchoud. CERS Journals Ltd 1996.

ABSTRACT: The influence of pulmonary resection on functional capacity can be assessed in different ways. The aim of this study was to compare the effect of lobectomy and pneumonectomy on pulmonary function tests (PFT), exercise capacity and perception of symptoms.

Sixty eight patients underwent functional assessment with PFT and exercise testing before (Preop), and 3 and 6 months after lung resection. In 50 (36 males and 14 females; mean age $61 \mathrm{yrs}$ ) a lobectomy was performed and in 18 (13 males and 5 females; mean age 59 yrs) a pneumonectomy was performed.

Three months after lobectomy, forced vital capacity (FVC), forced expiratory volume in one second (FEV1), total lung capacity (TLC), transfer factor of the lungs for carbon monoxide $(T L, C O)$ and maximal oxygen uptake $\left(V^{\prime} \mathrm{O}_{2}, \max \right)$ were significantly lower than Preop values, increasing significantly from 3 to 6 months after resection. Three months after pneumonectomy, all parameters were significantly lower than Preop values and significantly lower than postlobectomy values and did not recover from 3 to 6 months after resection. At 6 months after resection significant deficits persisted in comparison with Preop: for FVC $7 \%$ and 36\%, FEV1 $9 \%$ and $34 \%$, TLC $10 \%$ and $33 \%$ for lobectomy and pneumonectomy, respectively; and $V^{\prime} \mathrm{O}_{2}$,max $20 \%$ after pneumonectomy only. Exercise was limited by leg muscle fatigue in 53\% of all patients at Preop. This was not altered by lobectomy, but there was a switch to dyspnoea as the limiting factor after pneumonectomy $(61 \%$ of patients at 3 months and $50 \%$ at 6 months after resection). Furthermore, pneumonectomy compared to lobectomy led to a significantly smaller breathing reserve (mean \pm sD) $(28 \pm 13$ vs $37 \pm 16 \%$ at 3 months; and $24 \pm 11 \%$ vs $33 \pm 12 \%$ at 6 months post resection) and lower arterial oxygen tension at peak exercise $10.1 \pm 1.5$ vs $11.5 \pm 1.6$ $\mathrm{kPa}(76 \pm 11$ vs $86 \pm 12 \mathrm{mmHg})$ at 3 months; $10.1 \pm 1.3$ vs $11.3 \pm 1.6 \mathrm{kPa}(76 \pm 10$ vs $85 \pm 12$ $\mathrm{mmHg}$ ) at 6 months postresection.

We conclude that measurements of conventional pulmonary function tests alone overestimate the decrease in functional capacity after lung resection. Exercise capacity after lobectomy is unchanged, whereas pneumonectomy leads to a $20 \%$ decrease, probably due to the reduced area of gas exchange.

Eur Respir J., 1996, 9, 415-421.
Division of Pneumology, Dept of Internal Medicine and Cardiothoracic Unit, Dept of Surgery, University Hospital, Basel, Switzerland

Correspondence: C.T. Bolliger

Division of Pneumology

Dept of Internal Medicine

University Hospital

Petersgraben 4

CH - 4031 Basel

Switzerland

Keywords: Exercise capacity

lung resection

pulmonary function

Received: April 201995

Accepted after revision November 61995

This study was supported by grants from the Swiss Society of Pneumology and the Foundation for Pneumology, Basel, Switzerland.
The majority of lung resection candidates in industrialized nations suffer from bronchogenic carcinoma. Despite recent advances in chemo- and radiotherapy regimens surgical resection still remains the only curative form of treatment. Depending on their extent, pulmonary resections lead to permanent loss of pulmonary function. In healthy people, resections up to a pneumonectomy are remarkably well tolerated. Lung cancer patients, however, are mainly smokers or ex-smokers who not only suffer from their neoplasm, which should be resected, but also from varying degrees of chronic obstructive pulmonary disease (COPD) or ischaemic heart disease. This puts them at increased risk for postoperative complications and permanent respiratory disability.

Two questions have, thus, to be addressed at the time of the preoperative functional assessment: 1) are the cardiopulmonary reserves sufficient for the patient to survive an operation (operability); and 2) will the patient be chronically incapacitated due to insufficient pulmonary function (resectability) [1]. Various studies have investigated the functional loss after lung resection in terms of pulmonary function tests (PFT) [2-10]. It is generally accepted that resections involving not more than one lobe lead to an early loss in PFT with later recovery and little permanent deficit, whereas pneumonectomies cause a bigger permanent functional loss [7, 10].

An important complementary parameter for the assessment of the patient's functional status is his exercise capacity, which has been analysed less often [11-14] and does not necessarily correlate with the PFT [14]. We have recently reported on the importance of exercise capacity in the preoperative functional evaluation for the 
prediction of the immediate postoperative outcome in a series of 80 consecutive lung resection candidates [15]. The purpose of this study was to compare the postoperative decrease in PFT with the decrease in exercise capacity in these patients, and to determine whether the relative loss in exercise capacity could be inferred from conventional PFT. In addition, we wanted to analyse what factors limited exercise capacity after pulmonary resection. The study was approved by the University of Basel Ethics Committee, and all patients had given their written informed consent.

\section{Methods}

\section{Study population}

Of 80 consecutive patients (57 males and 23 females) with a mean age of 61 yrs (range 30-78 yrs) who underwent lung resection at our institution between January 1991 and December 1992, 68 were re-evaluated 3 and 6 months postoperatively. Twelve patients could not be reevaluated for the following reasons: three died in the hospital within 30 days after the operation (respiratory failure (2), acute myocardial infarction (1)); four patients were successfully discharged from hospital and died 3-6 months postoperatively (metastases from their bronchogenic carcinoma (2), heart failure (1), pulmonary embolism (1)); three patients were not able to perform representative pulmonary function and exercise tests because of acute exacerbations of their COPD; and two patients refused to complete the study. The 68 remaining patients were divided into two groups: lobectomy group (L-group), 50 patients (mean age 61 yrs (range 30-78 yrs), mean forced expiratory volume in one second (FEV1) $2.38 \pm 0.79 \mathrm{~L}, 36$ males and 14 females); and pneumonectomy group (P-group), 18 patients (mean age 59 yrs (range 46-73 yrs), mean \pm sD FEV1 2.5 \pm 0.47 L, 13 males and 5 females). The L-group consisted of 34 simple lobectomies, nine resections of less than an entire lobe (segmentectomies, wedge resections), five extended lobectomies, and two right upper bilobectomies. The maximum number of segments removed in the L-group was five. No specific postoperative rehabilitation programme was provided for the patients, but the smokers were encouraged to stop.

\section{Pulmonary function tests}

Spirometry and body-plethysmography were performed using the Masterlab (Jäger, Würzburg, Germany). The measurements of the flow-volume loops were recorded according to American Thoracic Society (ATS) criteria [16]. The following parameters were assessed: the flow/ volume loop (FEV1/forced vital capacity (FVC), static lung volumes (total lung capacity (TLC), the transfer factor of the lungs for carbon monoxide $(T \mathrm{~L}, \mathrm{CO})$ and the transfer coefficient for carbon monoxide $(K \mathrm{CO})$, and an arterial blood sample (arterial oxygen tension $\left(\mathrm{Pa}_{\mathrm{a}} \mathrm{O}_{2}\right)$, and arterial carbon dioxide tension $\left.\left(P \mathrm{a}, \mathrm{CO}_{2}\right)\right)(\mathrm{ABL} 500$, Radiometer, Copenhagen). In patients with obstructive airflow limitation the PFT were repeated after several days of intensive antiobstructive therapy, and the best test was recorded.

\section{Exercise tests}

After written informed consent had been obtained, all patients underwent symptom-limited cycle ergospirometry (cycle: ER 900L, Jäger; cardiopulmonary stress testing unit: EOS Sprint, Jäger, Würzburg, Germany). Baseline measurements were recorded after a minimal resting period of $3 \mathrm{~min}$ on the bicycle. The patients then started exercising at constant speed $(60 \mathrm{rpm})$. After a 2 min warm-up period at $20 \mathrm{~W}$ a ramp protocol with a 20 $\mathrm{W} \cdot \mathrm{min}^{-1}$ workload increase was started. The exercise test was stopped when the patients were exhausted, when a plateau in oxygen consumption $\left(V^{\prime} \mathrm{O}_{2}\right)$ appeared, or at any electrocardiographic (ECG) signs or symptoms of myocardial ischaemia, including a fall in blood pressure. All parameters were recorded until the end of a 6 min recovery period. Continuous measurements of minute ventilation $\left(V^{\prime} \mathrm{E}\right), V^{\prime} \mathrm{O}_{2}$, carbon dioxide production $\left(V^{\prime} \mathrm{CO}_{2}\right)$, and pulse rate were averaged every $15 \mathrm{~s}$. Blood pressure was measured manually (Riva-Rocci) every minute. A precordial ECG (equivalent leads $\mathrm{V}_{1}$, II and $\mathrm{V}_{5}$ ) was monitored continuously (Cardiotest EK 53 R; Hellige, Freiburg, Germany) and hard copies printed at rest, at peak exercise, at the end of the recovery period and, additionally, when arrhythmias or changes in the ST-Tsegments occurred. Arterial blood samples were drawn from the radial or brachial artery at rest and at peak exercise and analysed immediately. Maximal oxygen consumption $\left(V^{\prime} \mathrm{O}_{2}\right.$, max $)$ was recorded in $\mathrm{mL} \cdot \mathrm{kg} \cdot \mathrm{min}^{-1}$ and as a percentage of predicted normal values according to JONES [17]. The breathing reserve (BR) (in percent) was defined as:

$\frac{\operatorname{MVV}\left(\mathrm{L} \cdot \mathrm{min}^{-1}\right)-V^{\prime} \mathrm{E}\left(\mathrm{L} \cdot \mathrm{min}^{-1}\right) \text { at peak exercise } \times 100}{\operatorname{MVV}\left(\mathrm{L} \cdot \mathrm{min}^{-1}\right)}$

where MVV is maximum voluntary ventilation at rest, calculated as FEV1 $\times 40$ [18]. The heart rate reserve (HRR) in percent was defined as [18]:

Predicted maximum HR $-\mathrm{HR}$ at peak exercise $\times 100$ Predicted maximum HR

The subjective assessment of the exercise test was obtained with the use of the Borg category scale [19], and patients had to indicate their reason for stopping the exercise. If more than one reason was given the patient had to decide on the most relevant. For the statistical analysis, these reasons were divided into four major categories: 1) exhaustion; 2) muscle fatigue; 3) dyspnoea; and 4) other reasons, such as joint pain, mouth dryness, headache etc.

\section{Statistical analysis}

The comparison of all variables between the L-group and the P-group was made with the use of Student's t-test 
for continuous variables and the Chi-squared test for categorical variables. For each group, the change of each variable over time from before the operation (Preop) to 3 months and 6 months after the operation was analysed by a repeated measures analysis of variance (ANOVA) to assess an overall time effect, and for the comparison between two time-points (Preop to 3 months; 3 months to 6 months; and Preop to 6 months) by the paired t-test. The level of significance of all tests was chosen at alpha $<0.05$. Where applicable the measure of dispersion used throughout the study was the standard deviation.

\section{Results}

The values of the PFT and exercise measurements before the operation compared to 3 and 6 months after the operation are shown in table 1 and figures 1 and 2 . The representative variables chosen were FVC, FEV1 and TLC for lung volumes, TL,CO and KCO for gas exchange, $V^{\prime} \mathrm{O}_{2}$, max and maximal $\mathrm{W}$ for exercise capacity.

In the L-group the spirometry variables (FEV1, FVC and TLC) decreased significantly from Preop to 3 months

Table 1. - Summary table of preoperative (Preop), 3 months and 6 months postoperative PFTs and $V^{\prime} \mathrm{O}_{2}$, max values and percentage permanent functional loss $(\Delta \%)$

\begin{tabular}{|c|c|c|c|c|c|}
\hline & Group & Preop & 3 months & 6 months & $\Delta \%$ \\
\hline \multirow[t]{2}{*}{ FVC L } & $\mathrm{L}$ & $3.54 \pm 1.08$ & $3.16 \pm 0.91 *$ & $3.28 \pm 0.96^{*}$ & $-7.3^{+}$ \\
\hline & $\mathrm{P}$ & $3.67 \pm 0.9$ & $2.34 \pm 0.53 * \$$ & $2.34 \pm 0.61^{\$}$ & $-36.2^{+}$ \\
\hline \multirow[t]{2}{*}{ FEV1 L } & $\mathrm{L}$ & $2.38 \pm 0.79$ & $2.12 \pm 0.68 *$ & $2.17 \pm 0.73 *$ & $-8.8^{+}$ \\
\hline & $\mathrm{P}$ & $2.50 \pm 0.47$ & $1.65 \pm 0.29 * \$$ & $1.65 \pm 0.29 \$$ & $-34.0^{+}$ \\
\hline \multirow[t]{2}{*}{ TLC L } & $\mathrm{L}$ & $6.35 \pm 1.36$ & $5.56 \pm 1.26 *$ & $5.70 \pm 1.35 *$ & $-10.2^{+}$ \\
\hline & $\mathrm{P}$ & $6.22 \pm 1.39$ & $4.10 \pm 0.74 * \$$ & $4.19 \pm 0.94^{\$}$ & $-32.6^{+}$ \\
\hline \multirow[t]{2}{*}{$T \mathrm{~L}, \mathrm{CO} \quad \mathrm{mL} \cdot \mathrm{min}^{-1} \cdot \mathrm{mmHg}^{-1}$} & $\mathrm{~L}$ & $22.3 \pm 6.7$ & $20.4 \pm 5.7 *$ & $21.4 \pm 5.9 *$ & -4.0 \\
\hline & $\mathrm{P}$ & $22.8 \pm 6.7$ & $15.5 \pm 3.7 * \$$ & $16.4 \pm 3.7^{\$}$ & $-28.1^{+}$ \\
\hline \multirow{2}{*}{$V^{\prime} \mathrm{O}_{2}, \max \mathrm{mL} \cdot \mathrm{kg}^{-1} \cdot \min$} & $\mathrm{L}$ & $18.6 \pm 4.8$ & $16.9 \pm 4.9 *$ & $18.8 \pm 5.4 *$ & 1.0 \\
\hline & $\mathrm{P}$ & $18.9 \pm 5.6$ & $14.2 \pm 2.5 * \$$ & $15.1 \pm 2.7^{\$}$ & $-20.1^{+}$ \\
\hline
\end{tabular}

Values are presented as mean \pm SD. L: lobectomy; P: pneumonectomy; PFTs: pulmonary function tests; $V^{\prime} \mathrm{O}_{2}$, max: maximal oxygen consumption; FVC: forced vital capacity; FEV1: forced expiratory volume in one second; TLC: total lung capacity; TL,CO: transfer factor of the lungs for carbon monoxide. $*$ : $p<0.05$, compared to previous test; ${ }^{+}: p<0.05$, preoperative compared to 6 months postoperative; $\$$ : $\mathrm{p}<0.05$, lobectomy compared to pneumonectomy; $\Delta \%$ : $\%$ change preoperative to 6 months postoperative.
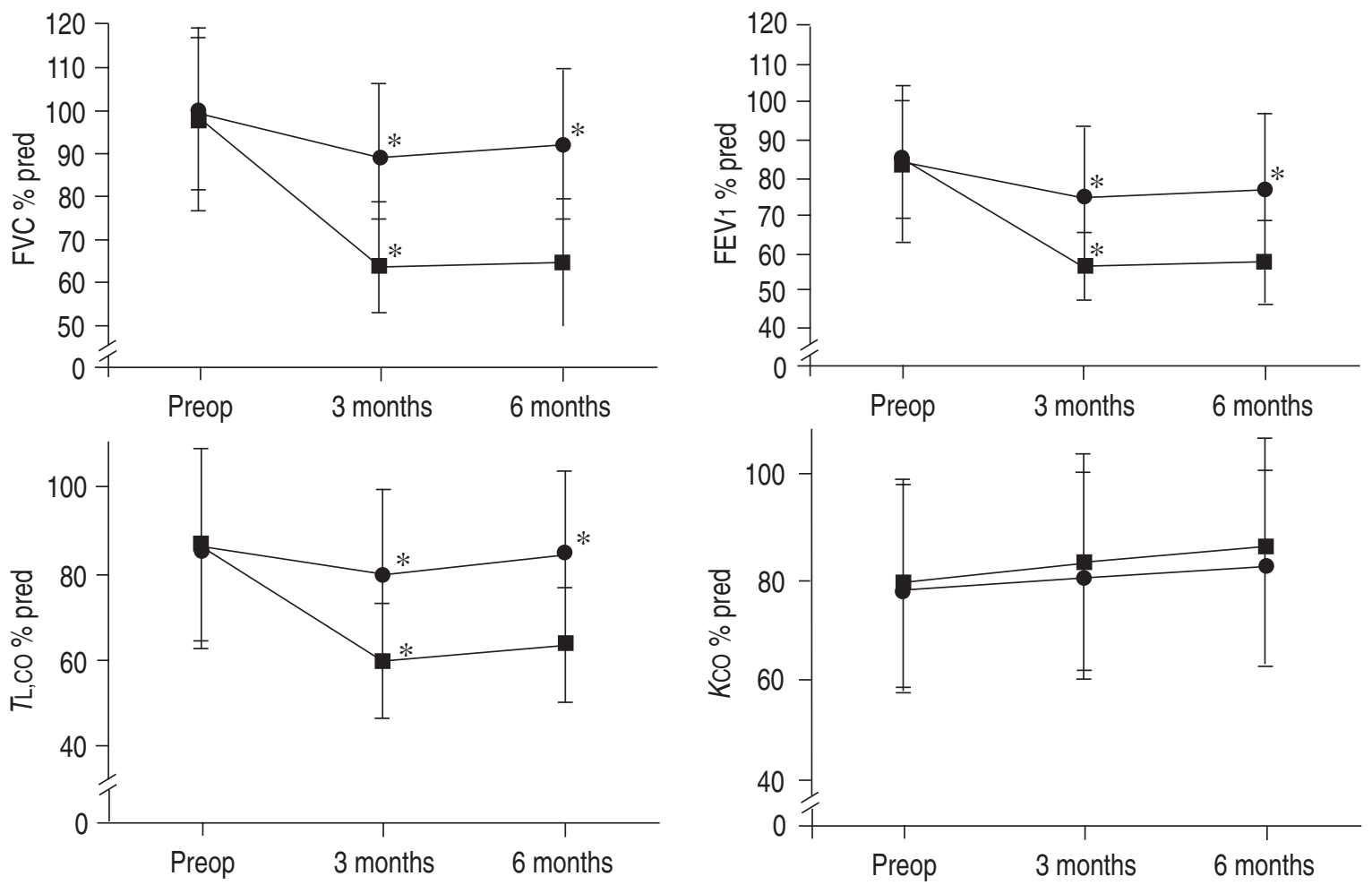

Fig. 1. - Dynamic lung volumes and transfer factor for carbon monoxide before, 3 and 6 months after pulmonary resection. *: $\mathrm{p}<0.05$ in comparison to previous test. Values are presented as mean \pm SD. FVC: forced vital capacity; FEV1: forced expiratory volume in one second; TL,CO: transfer factor of the lungs for carbon monoxide; KCO: carbon monoxide transfer coefficient. lobectomy $(\mathrm{n}=50)$; — 

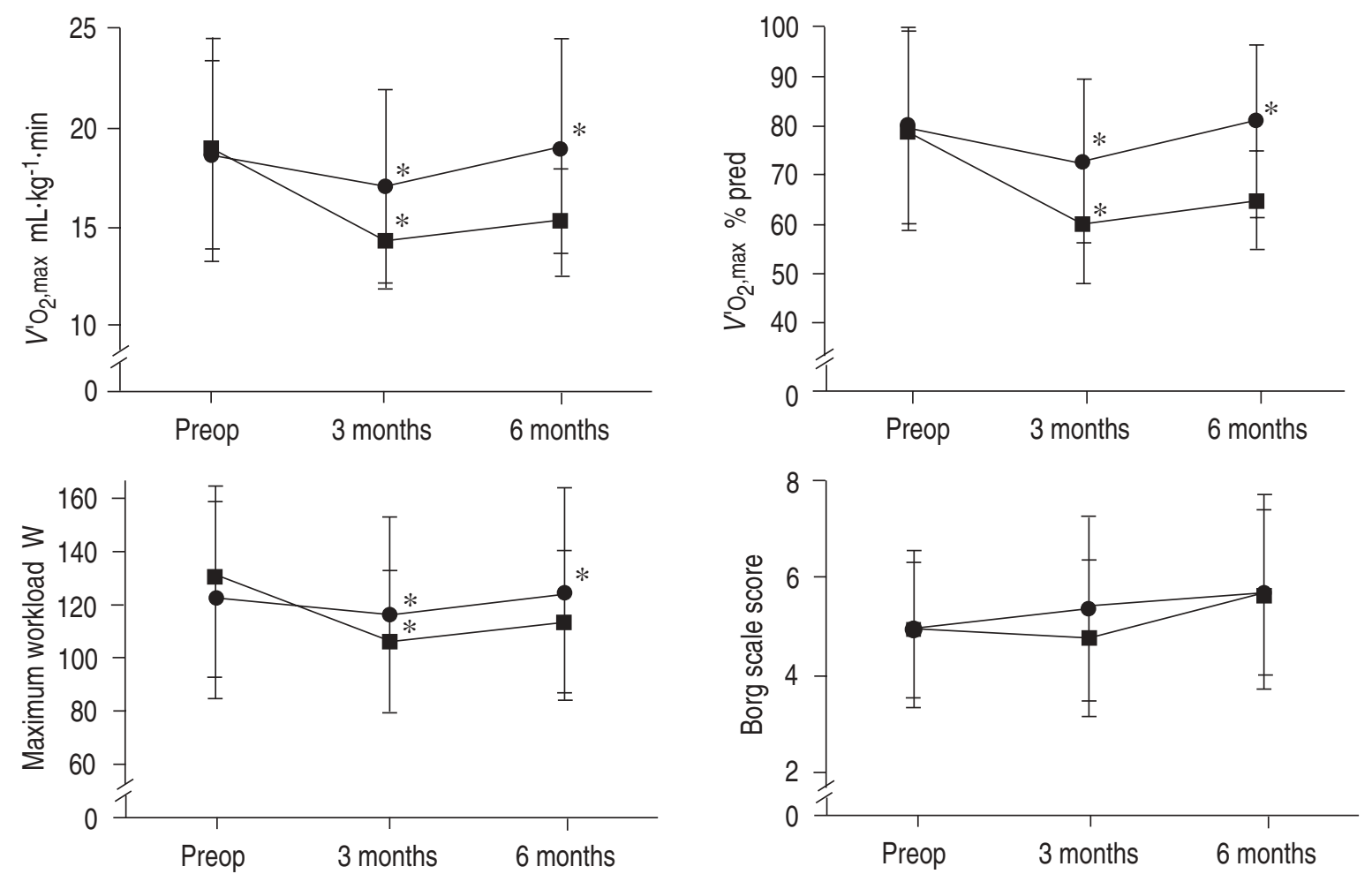

Fig. 2. - Exercise capacity and perceived exertion before, 3 and 6 months after pulmonary resection. $*$ : $\mathrm{p}<0.05$ in comparison to previous test. Values are presented as mean $\pm \mathrm{sD}$. $V^{\prime} \mathrm{O}_{2}$, max: maximal oxygen consumption; Preop: before resection. $-\longrightarrow$ lobectomy $(\mathrm{n}=50)$; — : pneumonectomy $(\mathrm{n}=18)$.

after the operation and increased again significantly from 3 to 6 months post resection (table 1 and fig. 1). In comparison to the preoperative measurements the values at 6 months were significantly lower (table 1). The functional loss was, however, small: FVC -7\%; FEV1 -9\%; and TLC $-10 \%$. The TL,CO showed similar changes, the functional loss at 6 months was $-4 \%$, whereas the transfer coefficient $(K \mathrm{CO})$ showed no change over time (fig. 1). Exercise capacity $\left(V^{\prime} \mathrm{O}_{2}, \mathrm{max}\right)$ also decreased from Preop to 3 months after the operation but increased to the preoperative values at 6 months (fig. 2). Lobectomy thus led to an early functional deficit at 3 months, followed by significant recovery at 6 months postoperatively. The permanent loss in PFT was maximally $10 \%$ with no loss in exercise capacity.

In the pneumonectomy group, all functional variables with the exception of KCO decreased significantly from Preop to 3 months after the operation and significantly more so than in the lobectomy group. In contrast to the lobectomies, none of the PFT or the exercise parameters showed significant recovery from 3 to 6 months postoperatively. The permanent functional deficit at 6 months in the pneumonectomies was for the spirometric values $\mathrm{FVC}-36 \%, \mathrm{FEV} 1-34 \%$, and TLC $-33 \%$; for $T \mathrm{~L}, \mathrm{CO}-28 \%$ and for $V^{\prime} \mathrm{O}_{2}$, max $-20 \%$ (table 1). The loss in $V^{\prime} \mathrm{O}_{2}$, max was similar whether analysed in absolute $(\mathrm{mL}$. $\mathrm{kg}^{-1} \cdot \mathrm{min}$ ) (table 1$)$ or in percentage of predicted values (fig. 2).

All patients exercised to exhaustion at all three timepoints. Their subjective assessment of the intensity of the exercise did not show significant intraindividual variability over time, which is reflected by virtually identical Borgscale values over time (fig. 2). For both groups, the level was 5 (scale 0-10) before the operation and showed a slight increase over 3-6 months postoperatively. The objective measurements of the $\mathrm{pH}$, base excess (BE) and the gas exchange ratio (R) $\left(V^{\prime} \mathrm{CO}_{2} / V^{\prime} \mathrm{O}_{2}\right)$ confirm the patients' subjective assessments: there was no change over time and no difference between the lobectomy and pneumonectomy group (table 2).

Patients were also asked to give the reason why they had to stop exercising at each time-point. Before the operation all 68 patients could be asked. At 3 and 6 months after the operation, only 64 patients were able to give subjective ratings of the factors limiting exercise (table 3 ), in four patients the answers were ambiguous. Before the operation, a small majority in the lobectomy (52\%) and pneumonectomy $(56 \%)$ group stopped because of leg muscle fatigue. Three and 6 months after the operation this percentage did not change significantly in the lobectomy group (54 and 46\%, respectively), whereas in the pneumonectomy patients the leading cause became dyspnoea (61 and 50\%, respectively). Thus, before the operation pneumonectomy and lobectomy patients had identical experience of the exercise intensity (Borg-scale) as well as the limiting factor. After the operation (3 and 6 months) the pneumonectomy patients still experienced the same intensity but were significantly more limited through dyspnoea than the lobectomy group $(\mathrm{p}<0.05$, Chi-squared).

These subjective assessments were compared to the corresponding objective measurements: ventilation $\left(V^{\prime} \mathrm{E}\right)$, 
Table 2. - Objective factors limiting exercise before (Preop), 3 months and 6 months after lung resection (all values measured at maximal exercise)

\begin{tabular}{|c|c|c|c|c|c|}
\hline & & Group & $\begin{array}{l}\text { Preop } \\
(n=68)\end{array}$ & $\begin{array}{c}3 \text { months } \\
(\mathrm{n}=68)\end{array}$ & $\begin{array}{c}6 \text { months } \\
(\mathrm{n}=68)\end{array}$ \\
\hline$V^{\prime} \mathrm{E} \quad \mathrm{L} \cdot \mathrm{I}$ & $\cdot \min ^{-1}$ & $\begin{array}{l}\mathrm{L} \\
\mathrm{P}\end{array}$ & $\begin{array}{l}54.3 \pm 17 \\
56.1 \pm 17\end{array}$ & $\begin{array}{l}51.3 \pm 17 \\
47.1 \pm 11^{*}\end{array}$ & $\begin{array}{l}57.4 \pm 17^{+} \\
50.6 \pm 12\end{array}$ \\
\hline$f \mathrm{R}$ brea & eaths $\cdot \min ^{-1}$ & $\begin{array}{r}{ }^{1} \mathrm{~L} \\
{ }^{\mathrm{P}}\end{array}$ & $\begin{array}{l}36 \pm 8 \\
34 \pm 7\end{array}$ & $\begin{array}{l}36 \pm 8 \\
40 \pm 7^{+}\end{array}$ & $\begin{array}{l}38 \pm 7 \\
41 \pm 5\end{array}$ \\
\hline BR \% & & $\begin{array}{l}\mathrm{L} \\
\mathrm{P}\end{array}$ & $\begin{array}{l}41 \pm 17 \\
44 \pm 15\end{array}$ & $\begin{array}{l}37 \pm 16^{*} \\
28 \pm 13^{+\$}\end{array}$ & $\begin{array}{l}33 \pm 12^{*} \\
24 \pm 11^{\$}\end{array}$ \\
\hline HR & & $\begin{array}{l}\mathrm{L} \\
\mathrm{P}\end{array}$ & $\begin{array}{l}141 \pm 25 \\
137 \pm 22\end{array}$ & $\begin{array}{l}136 \pm 22 \\
141 \pm 20\end{array}$ & $\begin{array}{l}139 \pm 20 \\
140 \pm 18\end{array}$ \\
\hline HRR & $\%$ & $\begin{array}{l}\mathrm{L} \\
\mathrm{P}\end{array}$ & $\begin{array}{l}17 \pm 13 \\
20 \pm 13\end{array}$ & $\begin{array}{l}19 \pm 12 \\
16 \pm 13\end{array}$ & $\begin{array}{l}17 \pm 11 \\
17 \pm 12\end{array}$ \\
\hline$P \mathrm{a}, \mathrm{O}_{2}$ & $\begin{array}{l}\mathrm{kPa} \\
\mathrm{mmHg} \\
\mathrm{kPa} \\
\mathrm{mmHg}\end{array}$ & $\begin{array}{l}\mathrm{L} \\
\mathrm{P}\end{array}$ & $\begin{array}{c}11.3 \pm 1.7 \\
85 \pm 13 \\
10.7 \pm 1.3 \\
80 \pm 10\end{array}$ & $\begin{array}{c}11.5 \pm 1.6 \\
86 \pm 12 \\
10.1 \pm 1.5^{\$} \\
76 \pm 11^{\$}\end{array}$ & $\begin{array}{c}11.3 \pm 1.6 \\
85 \pm 12 \\
10.1 \pm 1.3^{\$} \\
76 \pm 10^{\$}\end{array}$ \\
\hline $\mathrm{Pa}_{\mathrm{a}} \mathrm{CO}_{2}$ & $\begin{array}{l}\mathrm{kPa} \\
\mathrm{mmHg} \\
\mathrm{kPa} \\
\mathrm{mmHg}\end{array}$ & $\mathrm{L}$ & $\begin{array}{l}5.1 \pm 0.7 \\
38 \pm 5 \\
5.1 \pm 0.8 \\
38 \pm 6\end{array}$ & $\begin{array}{c}4.9 \pm 0.7 \\
37 \pm 5 \\
4.8 \pm 0.7 \\
36 \pm 5\end{array}$ & $\begin{array}{c}4.9 \pm 0.8 \\
37 \pm 6 \\
4.8 \pm 0.7 \\
36 \pm 5\end{array}$ \\
\hline $\mathrm{pH}$ & & $\begin{array}{l}\mathrm{L} \\
\mathrm{P}\end{array}$ & $\begin{array}{l}7.37 \pm 0.04 \\
7.38 \pm 0.07\end{array}$ & $\begin{array}{l}7.36 \pm 0.04 \\
7.39 \pm 0.04\end{array}$ & $\begin{array}{l}7.36 \pm 0.04 \\
7.38 \pm 0.04\end{array}$ \\
\hline $\mathrm{BE}$ & & $\begin{array}{l}\mathrm{L} \\
\mathrm{P}\end{array}$ & $\begin{array}{l}-3.1 \pm 2.9 \\
-3.1 \pm 2.3\end{array}$ & $\begin{array}{l}-3.7 \pm 2.3 \\
-2.6 \pm 2.3\end{array}$ & $\begin{array}{l}-4.3 \pm 2.6 \\
-3.3 \pm 1.7\end{array}$ \\
\hline $\mathrm{R}$ & & $\begin{array}{l}\mathrm{L} \\
\mathrm{P}\end{array}$ & $\begin{array}{l}1.14 \pm 0.16 \\
1.13 \pm 0.10\end{array}$ & $\begin{array}{l}1.12 \pm 0.16 \\
1.16 \pm 0.13\end{array}$ & $\begin{array}{l}1.18 \pm 0.13 \\
1.19 \pm 0.08\end{array}$ \\
\hline
\end{tabular}

Values are presented as mean \pm SD. $V^{\prime} E$ : minute ventilation; $f R$ : respiratory frequency; $\mathrm{BR}$ : breathing reserve; $\mathrm{HR}$ : heart rate; HRR: heart rate reserve; $P \mathrm{a}, \mathrm{O}_{2}:$ arterial oxygen tension; $P \mathrm{a}_{\mathrm{a}} \mathrm{CO}_{2}$ : arterial carbon dioxide tension; $\mathrm{BE}$ : base excess; R: gas exchange ratio. For further abbreviations see legend to table $1 .^{+}: \mathrm{p}<0.01$, compared to previous test; $*: \mathrm{p}<0.05$, compared to previous test; $\$$ : p $<0.01$, comparison between lobectomy and pneumonectomy groups.

Table 3. - Subjective factors limiting exercise before Preop, 3 months and 6 months after lung resection (all values measured at maximal exercise)

\begin{tabular}{|c|c|c|c|c|}
\hline & Group & $\begin{array}{l}\text { Preop } \\
(n=64)\end{array}$ & $\begin{array}{l}3 \text { months } \\
(n=64)\end{array}$ & $\begin{array}{l}6 \text { months } \\
(\mathrm{n}=64)\end{array}$ \\
\hline \multirow[t]{2}{*}{ Exhaustion } & $\mathrm{L}$ & $10(22)$ & $6(13)$ & $12(26)$ \\
\hline & $\mathrm{P}$ & $1 \quad(5)$ & $1 \quad(6)$ & $3(17)$ \\
\hline \multirow[t]{2}{*}{ Dyspnoea } & $\mathrm{L}$ & 7 (15) & $8(17)$ & $9(20)$ \\
\hline & $\mathrm{P}$ & 4 (22) & $11(61) * \$$ & $9(50) * \$$ \\
\hline \multirow[t]{2}{*}{ Muscle fatigue } & e $\mathrm{L}$ & $24 \quad(52)$ & $25 \quad(54)$ & 21 \\
\hline & $\mathrm{P}$ & $10 \quad(56)$ & $4(22)^{* \$}$ & $2(11) * \$$ \\
\hline \multirow[t]{2}{*}{ Other } & $\mathrm{L}$ & 5 (11) & 7 (15) & $4 \quad(9)$ \\
\hline & $\mathrm{P}$ & 3 (17) & $2(11)$ & $4(22)$ \\
\hline
\end{tabular}

Values are numbers of patients with percentages in parentheses. *: $p<0.05$ compared to preoperative evaluation; $\$$ : $p<0.05$ comparison between lobectomy and pneumonectomy groups. For abbreviations see legend to table 1 .

breathing frequency $(f \mathrm{R})$, breathing reserve $(\mathrm{BR}), \mathrm{Pa}_{\mathrm{a}} \mathrm{O}_{2}$ and $P \mathrm{a}, \mathrm{CO}_{2}$ at peak exercise (table 2). There was a significant permanent decrease in $V^{\prime} E$ coupled with a significant increase in $f R$ after pneumonectomy but not after lobectomy. The BR decreased significantly in both groups, but, more importantly, BR also differed significantly between the two groups at 3 months $(37 \pm 16$ vs $28=13 \%)$ as well as at 6 months $(33 \pm 12$ vs $24 \pm 11 \%)$ postoperatively. The postoperative $\mathrm{Pa}_{\mathrm{a}} \mathrm{O}_{2}$ was also significantly lower after pneumonectomy compared to lobectomy, both at 3 months $(10.1 \pm 1.5$ vs $11.5 \pm 1.6 \mathrm{kPa}(76 \pm$ 11 vs $86 \pm 12 \mathrm{mmHg})$ ) and at 6 months $(10.1 \pm 1.3$ vs $11.3 \pm 1.6 \mathrm{kPa}(76 \pm 10$ vs $85 \pm 12 \mathrm{mmHg}))$. The $P_{\mathrm{a}, \mathrm{CO}_{2}}$, on the other hand, did not change over time within or between groups. Maximum heart rate (HR) and the heart rate reserve (HRR) also showed no change within or between groups.

The potential influence of adjuvant treatment on PFT and exercise capacity was analysed. Eight patients in the pneumonectomy group (44\%) underwent postoperative external beam irradiation to the mediastinum, one patient in the lobectomy group underwent postoperative chemotherapy because the pathological diagnosis of the resected tumour was small cell lung cancer. The only variable possibly influenced by radiotherapy was FEV1, which showed significantly lower values in the irradiated patients 6 months postoperatively $(1.7 \pm 0.5 \mathrm{vs} 2.1 \pm$ $0.7 \mathrm{~L})$.

\section{Discussion}

The results of this study show that pulmonary resections led to very different levels of functional impairment depending on the extent of resection but also on the time-point of postoperative analysis. Various previous reports have analysed functional loss in PFT after lung resection. Unfortunately, the time-points of analysis were quite different in some reports, making direct comparison difficult $[11,14]$. We decided on 3 and 6 months evaluation postoperatively for the following reasons. In our experience, patients invariably complain about some degree of chest pain during normal everyday activities during the first 2-3 months postoperatively. The performance of forced respiratory manoeuvres, such as a flow-volume loop or maximal exercise tests, can therefore be influenced by the healing process of the thoracic wall. We chose 3 months as the "early" time-point for evaluation beyond which further functional recovery is to be expected. This also allowed direct comparison with other reports, such as those by OLSEN et al. [4] and by Ali et al. [7] for the 3 month evaluation; or those by LODDENKEMPER et al. [10] and by VAN Mieghem et al. [13] for the 6 month evaluation. The second time-point at 6 months was chosen to evaluate the permanent functional loss. Veneskoski et al. [9] showed that beyond 6 months there is no significant further improvement in PFT. Interestingly, after heart-lung transplantation, the recovery of PFT is also maximal between 6 and 9 months postoperatively without significant further increase at 12 months [20]. We evaluated the permanent functional loss in our patients as early as possible to guarantee a high follow-up rate. In our series, $78 \%$ of patients had malignancies, which will unfortunately recur in a substantial percentage of patients and, will, thus, lead to a 
relatively high drop out rate already seen during the second half of the first year after the operation. In a paper by MARKos et al. [21], 55 patients had initially been studied, but only 22 were available for an assessment after $1 \mathrm{yr}$.

The lobectomy group in our study was somewhat nonhomogeneous. When analysed separately, however, the nine sublobar resections, the five extended lobectomies and the two right upper lobectomies showed no significant differences in comparison with the 34 simple lobectomies. We therefore decided to include the sublobar resections as well as the extended lobectomies and the bilobectomies in the lobectomy group. The postoperative functional evaluation of the upper bilobectomies clearly showed that these resections were closer to simple lobectomies than to pneumonectomies.

Our results show that the evaluation of the permanent functional loss is overestimated both for lobectomies and for pneumonectomies when using PFT alone. Lobectomies led to a permanent PFT loss of $\pm 10 \%$ but no loss in exercise capacity, whereas pneumonectomies showed a PFT loss of $\pm 30 \%$ but only $20 \%$ in $V^{\prime} \mathrm{O}_{2}$,max. These findings are encouraging for preoperative patient counselling and help to ease a patient's fear of being crippled by the operation. Our findings are in accordance with the study by Van Mieghem and Demedts [13], who examined 14 patients after lobectomy and 14 after pneumonectomy 6 months postoperatively.

Pelletier et al. [14] found a loss in exercise capacity of $28 \%$ after pneumonectomy and $20 \%$ after lobectomy. These results are difficult to compare to ours because of their early time-point of evaluation (mean 73 days after lobectomy and 62 days after pneumonectomy) and the wide range over which it took place (26-200 days). To our knowledge, our study is the first to examine PFT as well as exercise capacity preoperatively, during (at 3 months) and at the end of the recovery period (at 6 months) after lung resection.

Our results were obtained in a group of patients with relatively normal lung function, with a mean preoperative FEV1 of $84 \%$ of predicted (fig. 1). We were also interested to see whether patients with clearly impaired preoperative PFT would exhibit an identical postoperative functional evolution to the entire group. Of the original 80 patients [15], a subgroup of 25 patients with an FEV1 $<2 \mathrm{~L}$ or a $T \mathrm{~L}, \mathrm{CO}<50 \%$ of predicted had undergone split function studies to calculate the postoperative predicted PFT and $V^{\prime} \mathrm{O}_{2}$, max. In the 22 survivors of this subgroup, who were analysed and reported separately [22], the prediction of postoperative function was accurate, and the functional evolution was similar to that for the whole group. Six months after lung resection, the 17 lobectomy patients showed no significant functional deficits, whereas in the five pneumonectomy patients the decrease in PFT was similar, and the loss in $V^{\prime} \mathrm{O}_{2}$, max slightly higher when compared with the whole group (28vs 20\%). Again, the decrease in $V^{\prime} \mathrm{O}_{2}$, max was less than that in PFT. We therefore think that in lung resection candidates with borderline PFT, exercise testing could help to reduce the functional limits for operability.
Apart from assessing $V^{\prime} \mathrm{O}_{2}$,max, we were also interested in the factors limiting exercise capacity. We did this on an objective and subjective basis. In both groups, patients exercised to full exhaustion at all three timepoints, which is reflected in identical Borg scale values over time. The mean Borg scale value of around 5 at peak exercise has been confirmed in recent studies by MARCINIUK et al. [23] in patients with restrictive disorders, and by O'DonNell and WeBb [24] in patients with COPD. The objective measurements supported the patients' own assessment, where the values of $\mathrm{pH}, \mathrm{BE}$ and $\mathrm{R}$ did not change over time. An $\mathrm{R}$ of $>1.05$ is considered proof of satisfactory motivation during the exercise test [25]. Furthermore, the $\mathrm{pH}$ and $\mathrm{BE}$ values at maximal exercise in our patients were similar to those found by HANSEN et al. [25] in a group of shipyard workers with a mean age of 54 yrs.

When asked about the subjective reasons limiting the exercise capacity, half of the patients indicated leg muscle fatigue before the operation (53\%) (table 3). This probably reflects a certain deconditioning, which is supported by large preoperative breathing (BR) and heart rate reserves (HRR). A BR of $>40 \%$ and a HRR of $16-$ $19 \%$ indicate that neither the pulmonary nor the cardiovascular system clearly limited the exercise capacity before the operation. Three and 6 months postoperatively, only the respiratory parameters changed significantly in both groups.

Subjectively, leg muscle fatigue remained the limiting factor after lobectomy, whereas pneumonectomy led to an early and permanent limitation through dyspnoea in the majority of patients. Compared to lobectomy, pneumonectomy led to significantly smaller $\mathrm{BR}$ and $\mathrm{Pa}, \mathrm{O}_{2}$ values, but similar $P \mathrm{a}, \mathrm{CO}_{2}$ values at peak exercise. In our opinion, exercise capacity after pneumonectomy is, therefore, limited by the transfer capacity of the reduced alveolar surface, whilst alveolar ventilation remains adequate.

Our findings are in accordance with the study of Pelletier et al. [14], where lobectomy had little effect on postoperative dyspnoea, but pneumonectomy led to an appreciable increase during exercise. The fact that leg discomfort made an important contribution to exercise limitation not only after lobectomy but also after pneumonectomy in the latter study is probably due to the early postoperative evaluation (mean 62 after pneumonectomy).

In summary, our study showed that lobectomy leads to about $10 \%$ permanent loss in PFT but no loss in exercise capacity, whereas pneumonectomy leads to an early permanent loss in PFT of about $30 \%$, and $20 \%$ in $V^{\prime} \mathrm{O}_{2}$, max. Thus, the relative decrease in exercise capacity after lung resection cannot be inferred by conventional PFTs, which overestimate the functional loss.

The exercise capacity after lobectomy is primarily limited by leg muscle fatigue or deconditioning, but after pneumonectomy clearly by dyspnoea, which is probably due to the reduced area of gas exchange. Knowledge of these functional changes depending on the amount of resection is useful for preoperative counselling, including the estimation of the patient's postoperative working capacity. 


\section{References}

1. Bechard DE. Pulmonary function testing. In: Diagnostic Procedures For Thoracic Diseases. Philadelphia, W.B. Saunders, LoCicero J III, ed. 1992.

2. Kristersson S, Lindell S, Svanberg L. Prediction of pulmonary function loss due to pneumonectomy using ${ }^{133} \mathrm{Xe}-$ radiospirometry. Chest 1972; 62: 694-698.

3. Kristersson S, Arborelius MJ, Jungquist G, Lilja B, Svanberg L. Prediction of ventilatory capacity after lobectomy. Scand J Respir Dis 1973; 54: 315-325

4. Olsen GN, Block AJ, Tobias JA. Prediction of postpneumonectomy pulmonary function using quantitative macroaggregate lung scanning. Chest 1974; 66: 13-16.

5. Legge JS, Palmer KNV. Effect of lung resection for bronchial carcinoma on pulmonary function in patients with and without chronic obstructive bronchitis. Thorax 1975; 30: 563-565.

6. Berend N, Woolcock AJ, Marlin GE. Effects of lobectomy on lung function. Thorax 1980; 35: 145-150.

7. Ali MK, Mountain CF, Ewer MS, Johnston D, Haynie TP. Predicting loss of pulmonary function after pulmonary resection for bronchogenic carcinoma. Chest 1980; 77: 337-342.

8. Boysen PG, Harris JO, Block AJ, Olsen GN. Prospective evaluation for pneumonectomy using perfusion scanning. Chest 1981; 80: 163-166.

9. Veneskoski T, Sivijärvi ARA, Muittari A. Effect of lung resection on regional lung function assessed by ${ }^{133} \mathrm{Xe}$ radiospirometry. Lung 1982; 160: 45-55

10. Loddenkemper R, Gabler A, Gobel D. Criteria of functional operability in patients with bronchial carcinoma: preoperative assessment of risk and prediction of postoperative function. Thorac Cardiovasc Surg 1983; 31: 334-337.

11. DeGraff ACJ, Taylor HF, Ord JW, Chuang TH, Johnson RLJ. Exercise limitation following extensive pulmonary resection. J Clin Invest 1965; 44: 1514-1522.

12. Corris PA, Ellis DA, Hawkins T, Gibson GJ. Use of radionuclide scanning in the preoperative estimation of pulmonary function after pneumonectomy. Thorax 1987 ; 42: 285-291.
13. Van Mieghem W, Demetds M. Cardiopulmonary function after lobectomy or pneumonectomy for pulmonary neoplasm. Respir Med 1989; 83: 199-206.

14. Pelletier C, Lapointe L, LeBlanc P. Effects of lung resection on pulmonary function and exercise capacity. Thorax 1990; 45: 497-502.

15. Bolliger CT, Jordan P, Solèr M, et al. Exercise capacity as a predictor of postoperative complications in lung resection candidates. Am J Respir Crit Care Med 1995; 151: 1472-1480.

16. American Thoracic Society. Standardization of spirometry: 1987 update. Am Rev Respir Dis 1987; 136: 1285 1298.

17. Jones NL. In: Clinical exercise testing. 3rd edn. Philadelphia, W.B. Saunders, 1988.

18. Wasserman K, Hansen JE, Sue DY, Whipp BJ. In: Principles of exercise testing and interpretation. Philadelphia, Lea and Febiger, 1987.

19. Borg GAV. Psychophysical bases of perceived exertion. Med Sci Sports Ex 1982; 14: 377-381.

20. Tamm M, Higgenbottam TW, Dennis CM, Sharples LD, Wallwork J. Donor and recipient predicted lung volume and lung size after heart-lung transplantation. Am J Respir Crit Care Med 1994; 150: 403-407.

21. Markos J, Mullan BP, Hillman DR, et al. Preoperative assessment as a predictor of mortality and morbidity after lung resection. Am Rev Respir Dis 1989; 139: 902-910.

22. Bolliger CT, Wyser C, Roser H, Solèr M, Perruchoud AP. Lung scanning and exercise testing for the prediction of postoperative performance in lung resection candidates at increased risk for complications. Chest 1995; 108: 341-348.

23. Marciniuk DD, Watts RE, Gallagher CG. Reproducibility of incremental maximal cycle ergometer testing in patients with restrictive lung disease. Thorax 1993; $48: 897$.

24. O'Donnell DE, Webb KA. Exertional breathlessness in patients with chronic airflow limitation. Am Rev Respir Dis 1993; 148: 1351.

25. Hansen JE, Sue DY, Wasserman K. Predicted values for clinical exercise testing. Am Rev Respir Dis 1984; 129: S49-S55. 